\title{
The Potency of Phytoplankton in the Lakes of Universitas Indonesia (UI) as the "Carbon-Eater": A Preliminary Study in Revealing the Lake as a Possibly Another Carbon Bank
}

\author{
S. Zahra, Ardiantiono, D. Oktavia, and E. Hardian, Member, IACSIT
}

\begin{abstract}
Phytoplankton is well-known as microorganism that can undergo photosynthesis and can only be found in aquatic ecosystems. Universitas Indonesia (UI), Depok, has six lakes: Kenanga, Agathis, Mahoni, Puspa, Ulin, and Salam Lake. Those lakes are proved to have an important role in regulating water circulation in UI and surroundings. However, study about the role of those lakes in storing carbon which is resulted from photosynthesis done by phytoplankton has not been conducted yet. We have done this study by using the light-and-dark bottle method in five kinds of depth in each lake. That method is used to obtain net productivity (NP) value then the result converted into the carbon sequestration rate (CSR). Analysis of NP in each lake is done by comparing several parameters (depth, turbidity, and biomass). Result of our study shows that NP has negative correlation with every parameter we observed and has varied significance value, i.e. NP-depth (sig: 0.001), NP-turbidity (sig: 0.001), and NP-biomass (sig: 0.05). Based on calculations, six observed lakes have total of CSR in the amount of $12,88 \mathrm{~kg} /$ hour. Knowing these facts could improve our knowledge to determine what kind of lake which can be potentially used as carbon bank and maintain it wisely.
\end{abstract}

Index Terms-Carbon sequestration rate, lake, phytoplankton, primary productivity.

\section{INTRODUCTION}

The rise of carbon dioxide $\left(\mathrm{CO}_{2}\right)$ in the atmosphere has caused the increasing earth's temperature and often reffered to global warming. It can lead to another phenomenon which called climate change [1]-[3]. Climate change has many disadvantages such as distrupt ecosystem balance which can lead to catastrophe, reducing food avaibility, and spreading of germs. Nowadays, climate change mitigation and solution has become one of the main focus for the environmental studies. Many studies have been conducted about ecosystem roles, especially forest and coastal area, in storing the carbon stock and its relation to climate change mitigation [1], [3]-[5].

Scientists still argue about the roles of inland watershed in storing the global carbon stock, but an experiment shows shows that inland watershed plays an important role in the organic carbon cycle of the nature and needs to be considered in climate change mitigation strategy [6] Studies about inland watershed's productivity and its dynamics have been conducted since many years ago and have a strong correlation with its potency in storing carbon stock as primary productivity involving photosynthesis whose role is

Manuscript received August 15, 2013; revised September 30, 2013.

The authors are with Universitas Indonesia (UI), Indonesia (e-mail: sevenmapleleaves@gmail.com). one of important carbon cycles [7]-[12].

\section{A. Primary Productivity}

Primary productivity is the rate of organic carbon production by photosynthesis reaction in the given time. Gross primary productivity (GPP) is sum of total photosynthesis and respiration reactions done by producer in the given time. Net primary productivity or net productivity (NPP/NP) is sum of organic carbon synthesis when photosynthesis reaction counted without including respiration reaction values in the given time [13]. Difference in time (i.e. season, and daylight period) and location may cause the difference in physical, chemical, and biological condition in the inland watershed. Thus, it may affect the primary productivity as photosynthesis reaction is also going to be affected. Light is an important factor which is directly responsible for the primary productivity in inland watershed. Light penetration into the water will be reduced in relation to the water depth because the reflection and diffraction of light by the particles in the water may cause an exponential decrease in light intensity curve. Therefore, the photosynthesis reaction tends to occur in the surface area of the inland watershed or in the layer of the inland watershed that's still penetrated by the sufficient amount of light [13].

Distribution of photoautotroph biomass also affects the primary productivity of inland watershed. Biomass distribution can be occured temporally. Temporal distribution is highly related to annual and daily cycle of the sun, i.e. motile algae and its daily vertical migration. Temporal distributions can also occure because of the reproduction cycle, i.e. the increasing of some phytoplankton species in the certain months. Primary productivity can be used as an indicator of the fertility of inland watershed [14].

\section{B. Phytoplankton}

Phytoplankton is an autrotrophic plankton that can undergo photosynthesis reaction. Phytoplankton can be unicellular with size about $2 \mu \mathrm{m}$ or multicellular with size up to $8 \mathrm{~mm}$. Phytoplankton, like plants, can absorb $\mathrm{CO}_{2}$ from the atmosphere and synthesize $\mathrm{O}_{2}$ through photosynthesis reaction. Phytoplankton needs light (primarily from the sun) to undergo photosynthesis and it causes phytoplankton to be usually found in the layer of inland watershed that is still penetrated by sufficient amount of light [15].

\section{The Role of the Lakes}

Lake is an important ecosystem for life. Many organisms take advantages from lake for their survival, including human. Human use lake as drinking water source, fisheries, agricultural irrigation, industrial activities, and recreation 
[16]. Whereas lake also has important role in ecosystem.

Lake plays important role in global organic carbon cycle. Lake receives carbon from land in the form of organic and inorganic carbon, which can be dissolved or not. Lake is also place for mineralization of the organic carbon that comes from respiration and metabolism reactions of organisms inhabiting the lake. Many lakes release carbon dioxide into the atmosphere because of the saturation of carbon dioxide inside the water of lake. Carbon dioxide that is released into the atmosphere is generally comes from the respiration of the organisms inhabiting the lake [17].

Carbon dioxide of lake and atmosphere is absorbed through photosynthesis done by phytoplankton and plant inhabiting lakes. Therefore, those organisms should be considered as potential components of lake in playing role as carbon bank. The utilization of carbon dioxide as the main component of photosynthesis reaction (alongside with light) will reduce the carbon dioxide excess which is one of greenhouse effect gas and hopefully will become one of the solution for climate change phenomenon.

We conducted a study to see the potential roles of phytoplankton in the inland watershed as a natural carbon bank by using the modification of the previous study of inland watershed primary productivity. Our study takes place in the six lakes in Universitas Indonesia, Depok. Through this study, we try to calculate the amount of carbon that can be stored by phytoplankton by converting the total primary productivity from the lakes with total area of $227.000 \mathrm{~m}^{2}$. The information about potential roles of lakes in Universitas Indonesia as carbon bank, hopefully, will increase the concern about the importance of lake's existence as an ecological service for climate change mitigation.

\section{Methodology}

Data was collected on July 24th--26th and 29th--31st 2013 at six lakes located in Universitas Indonesia, Depok, Jawa Barat, Indonesia. Those six lakes are Kenanga lake (28.000 $\left.\mathrm{m}^{2}\right)$, Ulin lake $\left(72.000 \mathrm{~m}^{2}\right)$, Puspa lake $\left(20.000 \mathrm{~m}^{2}\right)$, Mahoni lake $\left(45.000 \mathrm{~m}^{2}\right)$, Salam lake $\left(42.000 \mathrm{~m}^{2}\right)$, and Agathis lake $\left(20.000 \mathrm{~m}^{2}\right)$ (Fig. 1). Five sample points have been made in each lake with their locations depend on the characteristic of the lake.

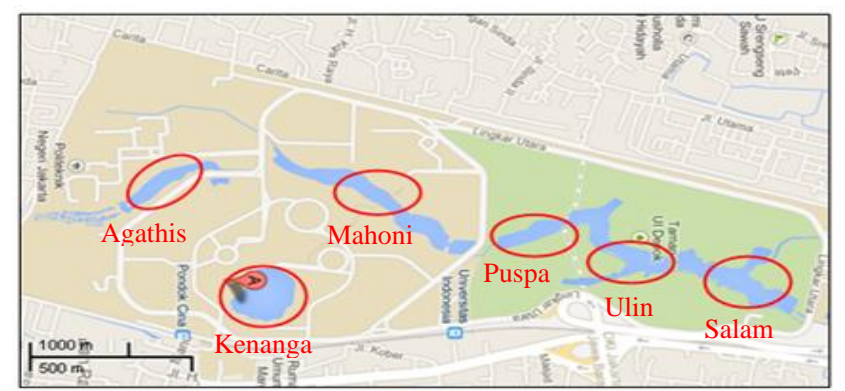

Fig. 1. Location of six lakes in Universitas Indonesia.

Light-and-dark bottle method has been used to collect the data. Those bottles were put in five depths, i.e. $\mathrm{cm} 0^{\text {th }}, \mathrm{cm}$ $10^{\text {th }}, \mathrm{cm} 30^{\text {th }}, \mathrm{cm} 50^{\text {th }}$, and $\mathrm{cm} 70^{\text {th }}$ from surface of the lake, in each sample point (Fig. 2). Water from each depth was collected by using the Nansen-bottle (volume: 2 litres), then was poured into the light and dark bottles. Each pair of light and dark bottle then exposed to water in its appropriate depth for 6 hours, started from around 09.00 a.m.--10.00 a.m. until around 03.00 p.m.--04.00 p.m. (in Western Indonesia Time). After 6 hours exposure, dissolved oxygen of water in each bottle is measured using multiparameter (model YSI-85) so that the primary productivity value can be counted. Value of primary productivity then was converted into the value of carbon by multiplying it with 0,375 . Another data that has been collected are biomass, depth of the lake, turbidity of the water, and light intensity.

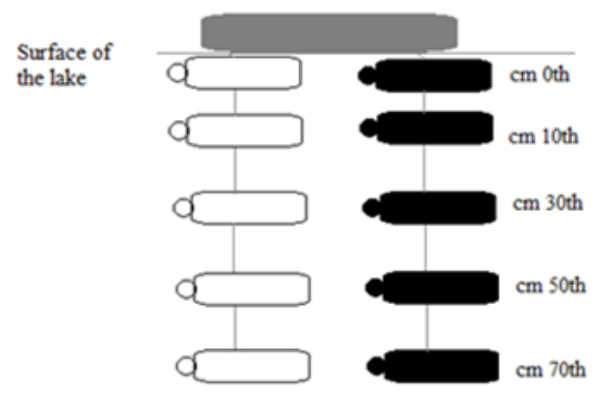

Fig. 2. Scheme of light/dark bottle positioning at one sample point

Biomass is measured by, firstly, filtering 100 litres of water of the lake by using plankton net. The filtered water was collected in the volume of $250 \mathrm{ml}$ as a sample. Secondly, the sample was centrifuged in $7.000 \mathrm{rpm}$ by using the centrifugator [International Clinical Sentrifuge-Model CL] in fifteen minutes. Thirdly, the biomass that has been centrifuged was separated from the water and put in the filtering paper (Whatman numb. 45). Lastly, the biomass was dried by using the oven [Precisa] in $50^{\circ} \mathrm{C}$ during thirty minutes. The dried biomass was then weighed using digital analytic scale weight measurer [Precisa].

\section{RESULT}

The highest Net Productiviy (NP) values of six lakes are generally found at $30 \mathrm{~cm}$ depth. The lowest NP values found at $70 \mathrm{~cm}$ depth. Minus sign (-) represents the state where the rate of respiration is higher than the rate of photosynthesis. Graphs can be seen in Fig. 3. Data of lake depth, turbidity, and the amount of biomass can be seen in Table I. More data such as volume, location and shape of lake can be seen in methods.

\begin{tabular}{ccccc}
\multicolumn{4}{c}{ TABLE I: PRIMARY DATA OF SIX LAKES IN UNIVERSITAS INDONESIA } \\
\hline Lake & Depth $(\mathrm{m})$ & Turbidity $(\mathrm{m})$ & $\begin{array}{c}\text { Biomass } \\
(\mathrm{g} / 100 \mathrm{~L})\end{array}$ & $\begin{array}{c}\text { Total Carbon } \\
\text { Seq. } \\
(\mathrm{kg} / \mathrm{lake} / \mathrm{hr})\end{array}$ \\
\hline Kenanga & $1,9-2,98$ & $0,13-0,145$ & 0,0352 & 0,796029 \\
Agathis & $0,8-1,29$ & $0,31-0,405$ & 0,0205 & 0,435323 \\
Mahoni & $0,77-2,27$ & $0,32-0,675$ & 0,0034 & 6,283195 \\
Puspa & $1,37-2,27$ & $0,4-0,47$ & 0,0104 & 1,170013 \\
Ulin & $0,72-3,38$ & $0,405-0,585$ & 0,0193 & 0,906627 \\
Salam & $2,09-3,64$ & $0,495-0,64$ & 0,028 & 3,236633 \\
\hline
\end{tabular}

Total carbon sequestration rate (CSR) of six lakes KAMPUS is $12.88 \mathrm{~kg} /$ hour. Total carbon sequestration rate values are obtained from the conversion of NP value into carbon values. The highest CSR value can be found in 
Mahoni lake with averaged 0.436 and varied from 0.189 to 0.566. while the lowest CSR can be found in Agathis lake with averaged 0.074 and varied from -0.004 to 0.160 . The average of two lakes are very different significantly ( $\mathrm{P}$ value $=0.01$ ). data can be seen in Fig. 4(left) NP data distribution in any depths of six lakes can be seen in Fig. 4 (right). The highest NP value lies at $30 \mathrm{~cm}$ depth with averaged of 0.559 and varied from 0.185 to 1.813 . The lowest NP value lies at $70 \mathrm{~cm}$ depth with averaged 0.051 and varied from -0.363 to $0.611(\mathrm{P}$ value $=0.001)$.

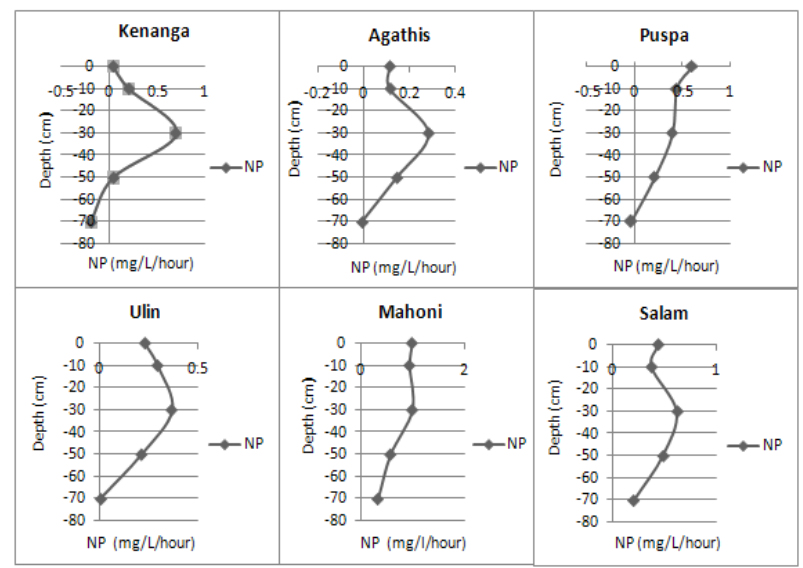

Fig. 3. Net productivity (NP) of six lakes in Universitas Indonesia.
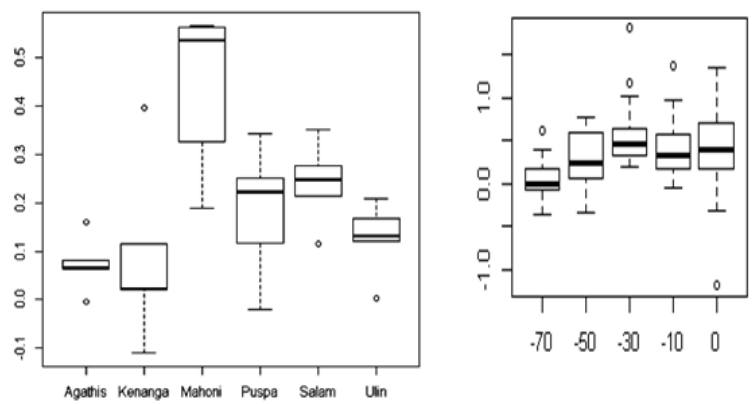

Fig. 4. Total carbon stock in the lakes of Universitas Indonesia (left); distribution of net productivity (NP) in every depth (right).

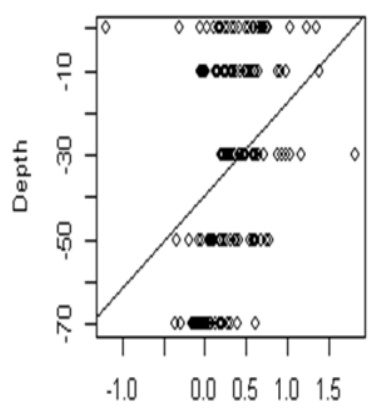

NP

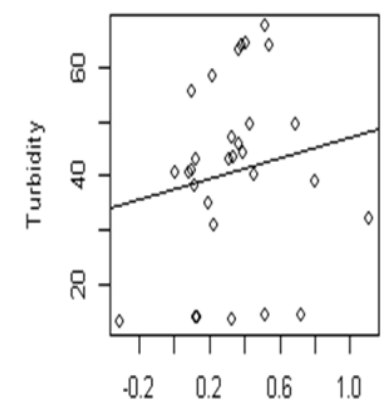

TNP
Fig. 5. Corelation between depth and net primary productivity (left); Correlation between turbidity and total net productivity from each sample (right).

Fig. 5 (right) shows a negative correlation between turbidity and NP $(P$ value $=0.001)$. At high turbidity level, productivity is low and tend to be negative. NP increases with decreasing turbidity and decrease with increasing depth. One-way ANOVA statistical test in Fig. 6 shows the level of NP and biomass of three category (High, Medium, Low) is not different significantly $(P$ value $=0.338)$ while the regression between biomass and NP shows negative correlation $(\mathrm{P}$ value $=0.05)$. Fig. 5 (left) shows a negative correlation between depth and NP $(\mathrm{P}$ value $=0.001)$

Fig. 7 (left) shows that Ulin lake has a depth that varies. It is likely related to the area of lake that reaches $72.000 \mathrm{~m}^{2}$ but the average depth of the lake itself is slightly the same as the Salam, Agathis, and Kenanga lake. Mahoni lake has a low range depth data, also the average depth is low either, followed by Puspa Lake. Fig. 7 (right) indicates that Mahoni lake has high-range turbidity data, which is inversely proportional to Kenanga and Salam lake which have low-range turbidity data, but Salam lake has very low turbidity levels.
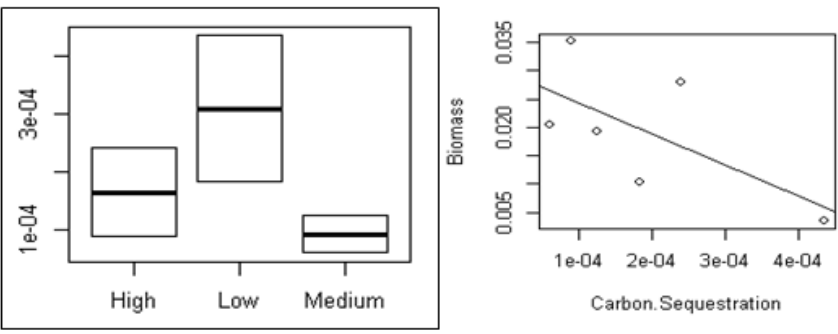

Fig. 6. ANOVA between total carbon sequestration and biomass value of each lake (left); Regression between total carbon sequestration and biomass value (right).
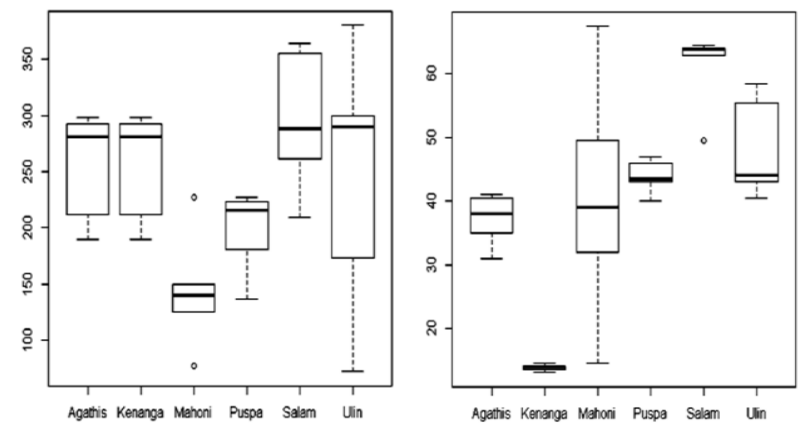

Fig. 7. Depth data distribution (left); Turbidity data distribution (right)

\section{DISCUSSION}

Net primary productivity (NPP) or Net Productivity (NP) is sum of organic carbon synthesis when photosynthesis reaction counted without including respiration reaction values in the given time [13]. Data of NP usually in the form of dissolved oxygen. We converted those data to carbon form by multiplying these values with photosynthesis equation (0.375). data that has been transformed called carbon sequestration rate (CSR). Every aspect that affect NP is going to affect CSR either. Our purpose use term of CSR is to predict and make an estimation how much carbon can potentially stored by phytoplankton on these lakes. Basically these term can be determined as something similar, remembering both of them affect one another.

Both NP and CSR are primarily affected by depth, turbidity, and biomass. From the result (Fig. 5), we conclude that depth ratio in photic zone of the lake affects the lake's NP. The correlation between the depth and NP is negative, means that the deeper the water, the lesser the NP. It depends on the phytoplankton found in the water of the lake. The phytoplankton needs light to do photosynthesis which involves carbon absorption. The radiation of light that 
penetrates the lake decreased rapidly with water depth. Because of that, the phytoplankton tends to live in the depth which is still penetrated with sufficient amount of light. That leads to the negative correlation between depth ratio and lake's NP [13], [18], [19] but total depth (photic + aphotic) of the lake itself does not significantly affect the amount of lake's NP because when light can not penetrate water there will be no photosynthesis occur thus NP in this zone can be count as zero and doesn't significantly affect [19].

Turbidity represents the extent to which light can penetrate into the body of water. In other words, turbidity can reduce the penetration of light into the body of water. Turbidity can also reduce the NP of the lake, because the more turbid the lake, the less light will be able to penetrate into the water [20]. In our study, the correlation between turbidity and NP is negative (Fig. 5). That condition leads to a fact that in our case, the turbid water is caused by the sediment particles. The greater amount of the sediment particles found in the water cause the water to be more turbid, reduce the light penetration, and eventually reduce the lake's NP.

Correlation between CSR and biomass is negative as the result of our study (Fig. 5). Negative correlation is commonly found in the relation between NP and richness of zooplankton [21] meanwhile, positive correlation is commonly found in relation between NP and richness of phytoplankton [21], [22]. The possibility of dominance of zooplankton in biomass is suggested as the cause of negative correlation [21]. Besides, certain species of phytoplankton has a very low ability in producing primary product because different phytoplankton species has different ability in producing primary product [23].

Most tropical lakes have very high levels of NP, except lakes with very high turbidity levels thus blocking the penetration of light [24]. Mahoni lake has the highest level of primary productivity that also means it has high rate of carbon sequestration. That reason makes Mahoni as a great model of carbon bank. High levels of NP and CSR happened in Mahoni because the lake has a high-range turbidity data. In other words, the penetration of light in this lake is highly varied. Salam lake ranked second because of its lowest level of turbidity. Puspa lake ranked third due to average turbidity level. Ulin Lake ranks fourth although this lake's turbidity levels almost as same as Puspa. Kenanga and Agathis lakes rank fifth and sixth due to the turbidity level, but Agathis is the lowest likely due to its surface area which is being invaded by water hyacinth. Data can be seen in Fig. 7 .

Our study shows that the carbon sequestration rate in the six lakes of Universitas Indonesia is $12,88 \mathrm{~kg} /$ hour. Some other studies say that many inland watersheds have heterotrophic Net Ecosystem Productivity (NEP) [G. M. Lovett]. Our study shows that the phytoplankton community in the lakes of Universitas Indonesia has an ability to actively absorb the carbon and a very important roles to determine the lake NEP. NEP is not similar with NP. NEP is the difference between GPP and Re (Respiration) from all biomass in the lake. NEP conceptually paralel with NP and represent $\mathrm{C}$ pottentially available for being stocked. An experiment Found the roles of inland watershed in global carbon cycle, and eventually, must be considered as a potential component in climate change mitigation. The existence of phytoplankton community, as the biggest producer in the lakes of Universitas Indonesia ecosystem, also plays an important roles to the carbon cycle [6].

Knowing every aspect that affect primary productivity and CSR giving us information about what kind of characteristic that highly productive lake probably has. These information later can be used as preliminary study for further advance experiment. In our case Mahoni lake is the most productive lake in Universitas Indonesia and should be maintained because of its potential roles for mitigating climate change by sequestrate and adsorb carbon.

Unfortunately, data about NP and CSR of phytoplankton in the lakes of Universitas Indonesia still cannot answer the main question: "is the carbon stored in a long period of time?". Another factors, i.e. total respiration rate, oxidation, export, and import of the carbon in the lake should also be considered to answer the question [25]. However, with knowing NP and CSR by phytoplankton in the lake, we can provide the initial data about the lake's potential role in absorbing and storing the carbon in relation to the phytoplankton role as the producer with the highest biomass in the lakes ecosystem [25], [26]. Therefore, with more comprehensive study, in the future, inland watershed's roles will be more considered as the potential carbon bank in the earth.

\section{CONCLUSION}

Results show that carbon sequestration rate of six lakes in Universitas Indonesia is $12.88 \mathrm{~kg} /$ hour. Both NP and CSR is affected primarily by depth, turbidity, and biomass. Correlation between NP and turbidity is negative due to light penetration. Correlation between carbon sequesteration and depth is also negative, as depth correlated with turbidity, but total depth of lake doesn't significantly affect NP. Correlation between CSR and biomass is tend to be negative because of the possibility that biomass content is not only phytoplankton but also zooplankton.

These days we seek every ecosystem that has potential for being carbon bank. Previous study has more concentrated in forest and been implemented through REDD+ program. Through our study, we try to expand the focus on inland watershed (in our case is lake) and its potential for being carbon bank which is still not widely known. Studying about factors that affect carbon sequestration rate is important to give us a proper knowledge that lakes can act as another carbon bank. Therefore, lakes should be conserved and used as carbon bank in the action of global warming and climate change mitigation. Further study needs to be conducted to get more specific and crucial knowledge.

\section{ACKNOWLEDGMENT}

Shafia Zahra thanks to Drs. Wisnu Wardhana, M. Si and Dra. Dian Hendrayanti, M. Sc as the supervisors in this study. S. Zahra thanks to Department of Biology and Mapala-Universitas Indonesia for lending us the equipments needed to conduct this study.

Shafia Zahra also thanks to Pembina Lingkungan Kampus-UI (PLK-UI), Sandy Leo, Khristian Anton Hartono, 
Rangga Ardiansyah, Sheherazade, and Ayu Novita Sari for helping us in conducting this study.

\section{REFERENCE}

[1] C. A. G. Hunt, Carbon Sinks and Climate Change: Forests in Fight Against Global Warming, U.K.: Edward Elgar Publishing Limited, 2009, pp 1-236.

[2] V. Smetacek et al., "Deep carbon export from a southern ocean iron-fertilized diatom bloom," Nature, vol. 487, pp. 313-319, 2012.

[3] F. A. Iwari, S. Wouthuyzen, M. P. Patria, and W. Kiswara, "Sequesteration rate and carbon stock on seagrass communities at Pramuka Island, Seribu Islands, Jakarta Capital City," in Proc. the International Symposium on Coastal Cities, Marine Resources, and Climate Change in the Coral Triangle, 2013, pp. 51.

[4] B. G. Mackey, H. Keith, S. L. Berry, and D. B. Lindenmayer, Green Carbon: The Role of Natural Forests in Carbon Storage. Canberra, Australia: ANUE Press, 2007, pp. 1-48.

[5] N. M. Ashuri and M. P. Patria, "Carbon stock analysis of mangrove ecosystem in Pancer Cengkrong, Trenggalek, East Java, Indonesia," in Proc. the International Symposium on Coastal Cities, Marine Resources, and Climate Change in the Coral Triangle, 2013, pp. 52.

[6] T. J. Battin et al., "The boundless carbon cycle," Nature Geoscience, vol. 2, pp. 598-600, 2009.

[7] P. Harry, J. Pumpanen, J Huotari et al., "High frequency measurements of productivity of planktonic algae using rugged nondipersive infrared carbon dioxide probes," Limnology and Oceanography: Methods, vol. 6, pp. 347-354, 2008.

[8] B. Hepher, "Primary production in fishponds and its application to fertilization experiments," Limnology and Oceanography, vol. 7, no. 2, pp. 131-136, 1962.

[9] A. Srenivaasan, "The limnology, primary production, and fish production in tropical pond," Limnology and Oceanography, vol. 9, no. 3, pp. 391-396.

[10] M. E. Blindloss, "Primary productivity of phytoplankton in Loch Leven, Kinross," in Proc. the Royal Society of Edinburgh Section B (Biology), 1974, vol. 74, pp. 157-181.

[11] Y. Cohen, W. E. Krumbein, and M. Shilo, "Solar Lake (Sinai): Distribution of photosynthetic microorganisms and primary production," Limnology and Oceanography, vol. 22, no. 4, pp. 609-620, 1977.

[12] R. E. Hecky and E. J. Fee, "Primary production and rates of algal growth in Lake Tanganyika," Limnology and Oceanography, vol. 26 , no. 3, pp. 532-547, 1981.

[13] A. Pitoyo and Wiryanto, "Produktivitas primer perairan Waduk Cenglik, Boyolali," Biodiversitas, vol. 3, no.1, pp. 189-195, 2002.

[14] T. A. Barus, S. S. Sinaga, and R. Tarigan, "Produktivitas primer fitoplankton dan hubungannya dengan faktor fisik-kimia air di perairan Parapat, Danau Toba," Journal Biologi Sumatera, vol. 3, no. 1, pp 11-16, bulan 2008.

[15] G. Lee and J. Stokes, Marine Science: An Illustrated Guide to Science, New York, USA: Chelsea House, 2006, pp. 113-114.

[16] N. G. Hairston Jr. and G. F. Fussmann, Encyclopedia of Life Science: Lake Ecosystems, New York, USA: Macmillan Publishers Ltd., 2002, pp. 1-3.

[17] L. J. Tranvik et al., "Lakes and reservoirs as regulators of carbon cycling and climate," Limnology and Oceanography, vol. 54, no. 6, pp. 2298-2314, 2009

[18] T. Hama, K. H. Shin, and N. Handa, "Spatial variability in the primary productivity in the East China Sea and its adjacent waters," Journal of Oceanography, vol. 53, pp. 41-51, 1997.

[19] D. W. Schindler, "Factors regulating phytoplankton production and standing crop in world's freshwater," Limnology and Oceanography, vol. 23 , no. 3, pp. 478-486, 1978

[20] D. S. Lloyd, "Turbidity in freshwater habitats of Alaska," Alaska Department of Fish and Game, pp. 1-102, 1985.
[21] S. I. Dodson, S. E. Arnott, and K. L. Cottingham, "The relationship in lake communities between primary productivity and species richness," Ecology, vol. 81, no. 10, pp. 2662-2679, 2000.

[22] P. W. Lehman, "The influence of phytoplankton community composition on primary productivity along the riverine to freshwater tidal continuum in the San Joaquin River, California," Estuaries and coasts, vol. 30, no. 1, pp. 82-93, 2007.

[23] N. M. M. Regina, M. C. Frank, and R. L. Miles, "Phytoplankton biomass and primary production dynamics in Lake Kariba," Lake and Reservoirs: Research and Management, vol. 17, pp. 275-289, 2012.

[24] M. Brylinsky and K. H. Mann, "An analysis of factors governing productivity in lakes and reservoirs," Limnology and Oceanography, vol. 18, no. 1, pp. 1-14, 1973.

[25] G. M. Lovett, J. M. Cole, and M. L. Pace, "Is net ecosystem production equal to ecosystem carbon accumulation," Ecosystem, vol. 9, pp. 152-155, 2006.

[26] J. J. Korhonen, J. Wang, and J. Soininen, "Productivity-diversity relationship in lake plankton communities," Plos ONE, vol. 6, pp. 1-11, 2011.

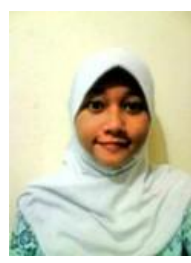

Shafia Zahra was born in Bogor, Indonesia on January 29, 1993. She is an undergraduate student at Universitas Indonesia (UI). She chooses biology as her field of study and Ecology as her major.

She has an experience as a laboratorium assistant in Ecology lecture and becomes a tutor at ligula ecotourism and a delegation from UI at ATBC in Aceh. she has an that field now. interest especially in Ecology and conduct a research in

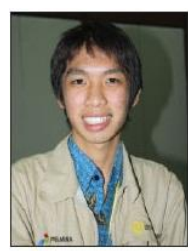

Ardiantiono was born in Pontianak, Indonesia on November 20, 1992. He is an undergraduated student at Universitas Indonesia (UI). He chooses biology as his field of study and Ecology as his major.

$\mathrm{He}$ has an experience as a laboratorium assistant in Genetic, and Animal structure lecture. He is a national champion of Pertamina Math and Natural Sciences Olympiad in 2011. And he was the silver medal winner of Math and Natural Sciences Olympiad in 2012. He is also a delegation in APRU 2013 at Vladiovovstok, Russia, and a delegation from UI at ATBC in Aceh. He has an interest especially in behaviour Ecology and conduct a research in that field now.

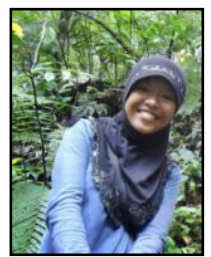

Dyna Oktavia was born in Tangerang, Indonesia on October 13, 1992. She is an undergraduate student at Universitas Indonesia (UI). She chooses Biology as her field of study and microbiology as her major.

She has an experience as a laboratorium assistant in Ecology lecture and a delegation from UI at ATBC in Aceh. She has interest especially in microbiology and conduct a research in that field now.

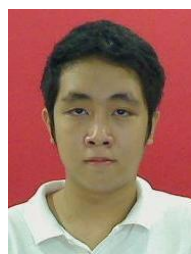

Erwin Hardian was born in Jakarta, Indonesia on May 2, 1992. He is an undergraduated student at Universitas Indonesia (UI). He chooses biology as his field of study, and animal physiology as his major.

He has an experience as a laboratorium assistant in Animal Structure and Physiology lecture. He has an interest especially in Animal Physiology and conducts a research in that field now. 